\title{
PEMANFAATAN DRONE UNTUK MONITORING AKURASI PERENCANAAN TAMBANG BATUBARA TERBUKA
}

\author{
Jhony $^{1)}$, Wildan Firdaus ${ }^{1)}$ \\ ${ }^{1)}$ Mine Desain \& Schedulling Expert, PT. Pamapersada Nusantara
}

\begin{abstract}
ABSTRAK
Pertambangan batubara di Indonesia telah mengalami pasang surut harga yang sangat fluktuatif sejak 2012. Hal tersebut berdampak langsung kepada para pelaku usaha pertambangan batubara. Oleh karena itu, efisiensi dalam proses pertambangan harus ditingkatkan termasuk dalam sisi perencanaan. Perencanaan yang baik dan akurat dapat memberikan banyak manfaat yaitu, peningkatan kualitas eksekusi dengan nilai stripping ratio yang optimum, tambang terbentuk rapi sehingga keselamatan kerja meningkat karena lereng terbentuk sesuai dengan desain serta meningkatkan utilisasi dan produktifitas alat. PT Pamapersada Nusantara merupakan salah satu kontraktor pertambangan batubara di Indonesia yang telah melakukan pengukuran akurasi perencanaan tambang sejak 2017 yang dikenal dengan nama MDA (Mine Design Accuracy). Nilai rata-rata MDA untuk proyek-proyek penambangan yang dikerjakan PAMA sejak 2017 hingga 2018 masih berkisar 91\%, artinya masih ada 9\% dari operasional yang diluar perencanaan baik yang berupa overcut maupun yang undercut dari desain awal. Untuk meningkatkan nilai MDA tersebut, dilakukan terobosan sistem monitoring operasional dengan bantuan drone. Bahkan drone tidak hanya dimanfaatkan untuk monitoring secara visual melalui video saja, tetapi juga digunakan sebagai alat ukur akurasi desain dalam bentuk orthophoto yang di-overlay-kan dengan desain dan cross section dari situasi hasil pemetaan menggunakan drone. Hasil video dari drone dilihat oleh pengawas tambang setiap hari dari sudut pandang yang lebih luas (helicopter view) dengan tujuan pengawas akan lebih jelas dalam menemukan deviasi dan dapat segera melakukan tindakan perbaikan. Hasil orthophoto yang di-overlay-kan dengan desain, dievaluasi secara mingguan oleh mine engineer untuk melihat posisi dan kelurusan tambang yang sedang dikerjakan apakah telah sesuai dengan desain perencanaan. Dan juga sebagai mitigasi terhadap potential problem yang akan muncul karena orthophoto dapat memberikan citra yang lebih jelas (real) dibandingkan hanya melihat kontur tambang. Sedangkan untuk cross section dari hasil situasi drone juga dapat dilakukan secara mingguan agar mine engineer dapat dengan cepat menginformasikan kepada pengawas di lapangan area mana saja yang sudah mendekati desain dan area mana yang masih harus digali. Setelah metode monitoring dan pengukuran menggunakan drone, nilai Mine Desain Accuracy meningkat menjadi 95\% di semester 1 tahun 2019. Hal ini berarti pemanfaatan teknologi drone dapat membuat operasional pertambangan yang lebih efektif karena baik pengawas maupun mine engineer sama-sama dapat melihat situasi tambang dengan lebih luas dalam kondisi real. Selain efektif, drone juga dapat meningkatkan efisiensi kerja karena waktu yang dibutuhkan untuk pengambilan situasi lapangan yang berupa video hingga berbentuk data situasi sangat singkat dibandingkan dengan pengambilan data dengan metode lainnya.
\end{abstract}

Kata Kunci: Mine Desain Accuracy, Drone, Stripping Ratio, Orthophoto, Cross Section

\begin{abstract}
Coal mining in Indonesia has experienced ups and downs in prices that have fluctuated greatly since 2012. This has had a direct impact on coal mining businesses. Therefore, efficiency in the mining process must be increased including in the planning side. Good and accurate planning can provide many benefits, improving the quality of execution with an optimum stripping ratio, the mine is neatly formed so the safety is increased because the slope is formed in accordance with the
\end{abstract}


design and increases the utilization and productivity of production unit. PT Pamapersada Nusantara is a coal mining contractor in Indonesia who has measured accuracy in mine planning since 2017, known as MDA (Mine Design Accuracy). The average MDA for mining projects undertaken by PAMA from 2017 to 2018 is still around 91\%, meaning that there are still 9\% of operations that are out of planning both in the form of overcuts and undercuts from the initial design.

To increase the MDA value, a breakthrough in the operational monitoring system was carried out with the help of drones. Drones are not only used for visual monitoring via video, but are also used as a measurement of design accuracy in the form of orthophoto that is overlaid with the design and cross section of the situation using the drone mapping results. The video results of the drone are seen by the mine supervisor every day from a broader perspective (helicopter view) with the aim of the supervisor being more clear in finding deviations and can immediately take corrective action. The orthophoto results that are overlaid with the design, are evaluated weekly by the mine engineer to see the position and alignment of the mine being worked on whether it is in accordance with the design plan. And also as a mitigation of potential problems that will arise because orthophoto can provide a clearer image (real) than just seeing the contours of the mine. Cross section of the drone situation results can also be done every week so that the mine engineer can quickly inform the field supervisor which areas are close to the design and which areas still need to be excavated.

After monitoring and measuring methods using drones, Mine Design Accuracy increased to $95 \%$ in semester 1 of 2019. This means that the use of drone technology can make mining operations more effective because both supervisors and mine engineers can see the mine situation more extensive in real conditions. Aside from being effective, drones can also improve work efficiency because the time needed to capture field situations in the form of video to form data is very short compared to data retrieval by other methods.

Kata Kunci: Mine Desain Accuracy, Drone, Stripping Ratio, Orthophoto, Cross Section

\section{A. PENDAHULUAN}

\section{A.1 Latar Belakang Masalah}

Indonesia merupakan Indonesia merupakan salah satu negara yang sangat kaya dengan sumber daya alamnya. Salah satu komoditas yang cukup besar di Indonesia adalah batubara. Sejak 2005, Indonesia merupakan salah satu produsen dan eksportir batubara thermal terbesar di dunia (sumber: www.indonesia-investments.com). Akan tetapi sejak tahun 2012, Harga jual batubara di Indonesia mengalami pasang surut yang sangat fluktuatif. Hal itu membuat banyak pelaku usaha pertambangan batubara di Indonesia memilih menutup usaha pertambangannya daripada terus menerus mengalami kerugian. Pemilik usaha batubara yang bertahan harus melakukan efisiensi pada usahanya disemua tahapan mulai dari perencanaan hingga produksi agar terus bertahan.

PT. Pamapersada Nusantara merupakan salah satu kontraktor batubara di Indonesia yang memiliki 15 jobsite penambangan batubara yang tersebar di Kalimantan dan Sumatra. Dari 15 customer yang berbeda, hampir semua customer menuntut PT. Pama agar dapat melakukan penambangan sesuai dengan Stripping Ratio (SR) yang direncanakan. Menanggapi hal tersebut, tim Engineering PT. Pama melalui Departemen Technical Service membuat suatu sistem kontrol penambangan di lapangan yang dinamakan Mine Design Accuracy (MDA). MDA merupakan suatu sistem yang dibangun untuk mengukur kesesuaian antara aktual penambangan di lapangan dengan mangkok design yang telah disepakati sebelumnya. Periode pengukuran MDA menggunakan periode bulanan sehingga mangkok penambangan menggunakan desain bulanan (monthly design) yang sudah disepakati dengan customer sesuai dengan kapasitas alat kerja yang tersedia (gambar 1). 


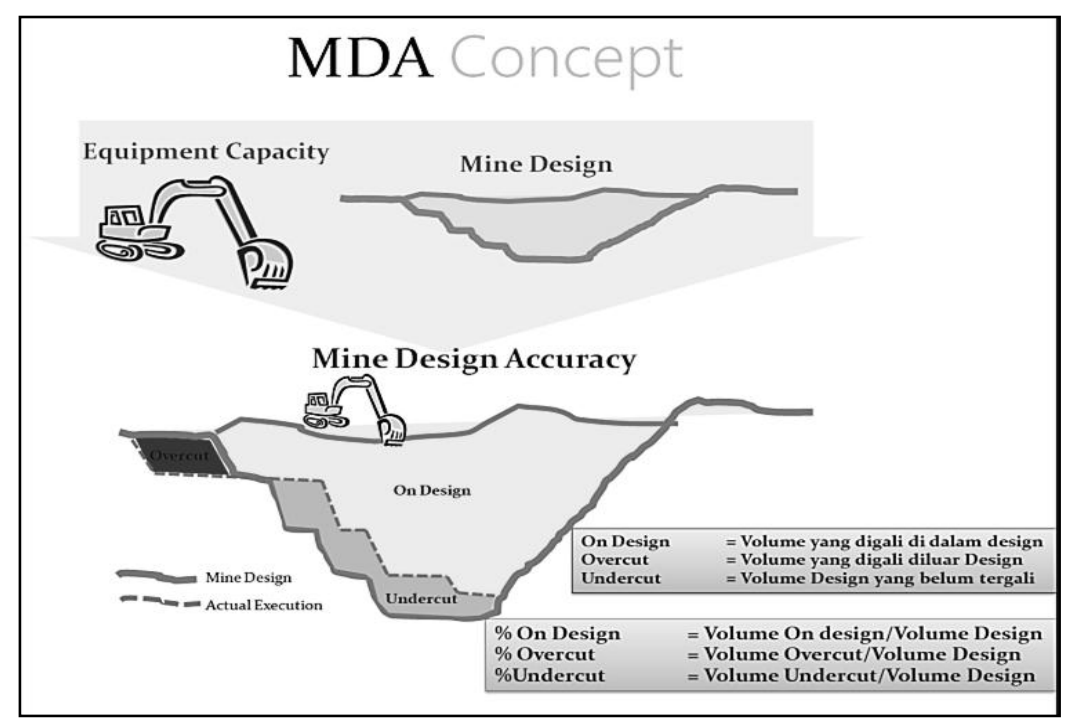

Gambar 1. Konsep mine design accuracy

Nilai MDA diperoleh dari prosentase aktual penambangan yang sudah sesuai dengan desain (on design) yang dikurangi dengan banyaknya volume yang diluar desain (baik overcut maupun undercut) seperti yang ditunjukkan pada gambar 2. Pengukuran MDA tidak hanya bertujuan untuk memenuhi permintaan customer dalam pencapaian SR saja, tetapi juga digunakan untuk mengontrol kerapihan lereng tambang agar keselamatan di lapangan dapat terjaga karena lereng terbentuk sesuai dengan desain.

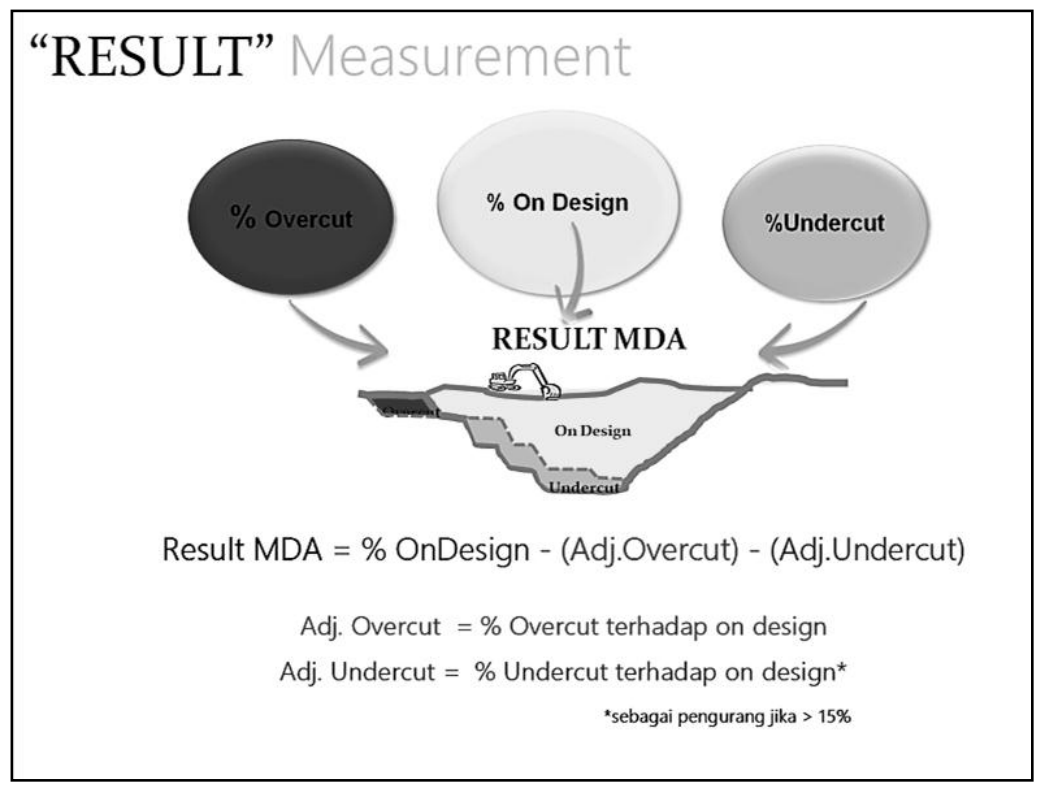

Gambar 2. Konsep mine design accuracy

Nilai MDA yang ditargetkan PT. Pama untuk setiap jobsite penambangan yang dikerjakannya harus di atas 95\%, akan tetapi rata-rata pencapaian MDA sejak 2017 hingga 2018 masih berkisar $91 \%$. Nilai tersebut berarti masih ada $9 \%$ aktual penambangan yang bekerja tidak sesuai dengan desain yang ada. Jika hal tersebut dibiarkan terus menerus, maka akan berakibat pencapaian SR yang tidak sesuai dengan permintaan customer. Kerugian-kerugian akibat missed operational pun dapat terjadi seperti pembentukkan lereng yang tidak sesuai desain sehingga berpotensi longsor (gambar 3). Bahkan pending payment atas volume yang telah dikerjakan PT. Pama oleh customer dapat terjadi karena volume tersebut berada di luar desain (overcut). 


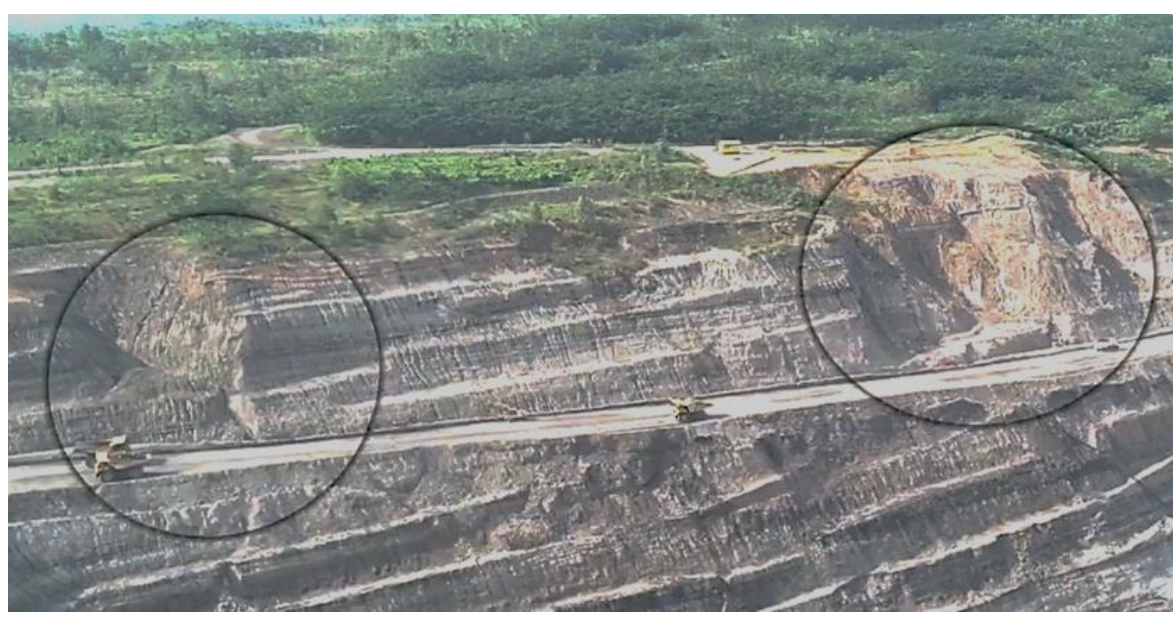

Gambar 3. Longsor yang terjadi akibat overcut terhadap desain

Untuk meningkatkan nilai MDA tersebut, diperlukan sistem monitoring operasional penambangan yang lebih advance dan komperehensif. Tim Technical Service Engineer PT. Pama mencoba untuk mengaplikasikan teknologi drone sebagai alat bantu untuk melakukan monitoring pekerjaan dilapangan. Drone adalah sebuah mesin terbang yang berfungsi dengan kendali jarak jauh oleh pilot atau mampu mengendalikan dirinya sendiri, menggunakan hukum aerodinamika untuk mengangkat dirinya, bisa digunakan kembali dan mampu membawa muatan baik senjata maupun muatan lainnya . Penggunaan terbesar dari pesawat tanpa awak ini adalah di bidang militer, tetapi juga digunakan di bidang fotografi dan videografi yang dilakukan secara bebas dan terbuka (sumber: https://id.wikipedia.org). Teknologi drone yang berkembang saat ini lebih banyak merupakan teknologi yang berbasis mainan yang digunakan untuk pengambilan video dan foto udara, bahkan sudah dapat dihasilkan pemetaan topografi dari hasil foto udara tersebut. Hasil pemetaan tersebut akan dimanfaatkan oleh tim engineer PT. Pama untuk membuat acuan perencanaan dan monitoring yang lebih detail. Adapun topik penelitian ini adalah melakukan kajian pemanfaatan drone untuk monitoring akurasi perencanaan tambang batubara terbuka.

\section{A.2. Tujuan Penelitian}

Tujuan dari penelitian ini antara lain adalah sebagai berikut:

1. Untuk mengetahui pemanfaatan drone sebagai alat bantu pengawasan operasional penambangan pada tambang batubara terbuka di jobsite penambangan PT. Pamapersada Nusantara.

2. Untuk mengetahui pemanfaatan hasil pemetaan topografi dari foto udara drone sebagai acuan perencanaan dan monitoring progress penambangan pada tambang batubara terbuka di jobsite PT. Pamapersada Nusantara.

3. Untuk mengetahui berapa besar pengaruh nilai MDA hasil pemanfaatan drone untuk monitoring akurasi perencanaan tambang batubara terbuka.

\section{A.3. Pendekatan Pemecahan Masalah}

Masalah yang akan diuraikan adalah masih adanya aktual penambangan yang dilakukan PT. Pama tidak sesuai dengan desain yang ada. Terdapat rata-rata 9\% dari perencanaan bulanan yang mengalami kelebihan penggalian (overcut) maupun kekurangan penggalian (undercut). Hal tersebut mengindikasikan adanya pengawasan yang kurang optimal dari pengawas dilapangan dan kurangnya monitoring progress penambangan oleh tim engineering sehingga mengakibatkan overcut dan undercut. Untuk meningkatkan pengawasan dan monitoring yang lebih baik, Technical Service Engineer PT. Pama akan memanfaatkan pengambilan video dan foto dilapangan menggunakan drone. Hasil dari video drone akan digunakan oleh pengawas dilapangan untuk melihat secara visual dari sudut pandang yang lebih luas aktual progress penambangan yang sedang dikerjakan. Hasil foto drone akan digunakan oleh tim engineering untuk membuat orthophoto dan dibandingkan dengan desain yang mereka buat. Hasil orthophoto akan diolah menjadi topografi 
aktual update yang dapat digunakan untuk acuan perencanaan mingguan yang lebh detail dan dapat dibuat cross section untuk monitoring terhadap desain sehingga tim engineer dapat menginformasikan kepada pengawas dilapangan mana area yang sudah mendekati desain dan area mana yang masih harus digali. Semua teknis perumusan metodologi, konsep, danmateri proses pembuatan topografi harus dipersiapkan terlebih dahulu sebelum pelaksanaan pengambilan video dan foto di lapangan (gambar 4).

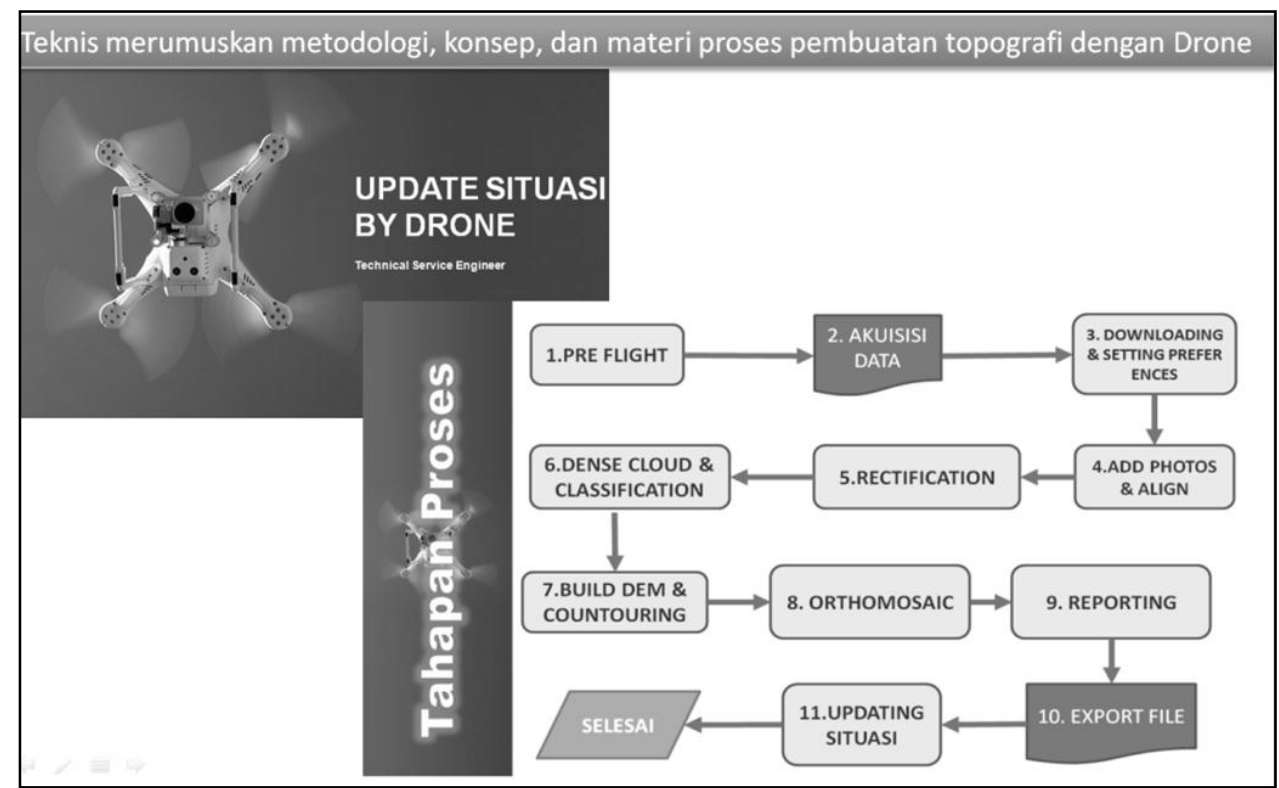

Gambar 4. Teknis merumuskan metodologi, konsep, dan meteri proses pembuatan topografi dengan drone

\section{B. METODOLOGI PENELITIAN}

\section{B. 1 Jenis Penelitian}

Apabila dilihat berdasarkan tujuannya, maka penelitian ini termasuk penelitian deskriptif. Penelitian dekriptif merupakan penelitian yang mengumpulkan data-data untuk menguji dugaan awal atau untuk menjawab pertanyaan penelitian mengenai status terakhir dari subyek penelitian. Apabila dilihat berdasarkan jenis datanya, maka penelitian ini termasuk penelitian kuantitatif. Penelitian kualitatif adalah penelitian tentang riset yang bersifat deskriptif dan cenderung menggunakan analisis. Proses dan makna (perspektif subjek) lebih ditonjolkan dalam penelitian kualitatif. Pada penelitian kualtitatif, peneliti memanfaatkan teori yang ada sebagai bahan penjelas, dan berakhir dengan suatu "teori" (sumber: https://id.wikipedia.org).

\section{B.2 Jenis dan Sumber Data}

Jenis data yang digunakan adalah data sekunder. Data sekunder adalah data yang diperoleh atau dikumpulkan peneliti dari berbagai sumber yang ada (peneliti sebagai tangan kedua). Data sekunder pada penelitian ini berupa data MDA, data video drone, data orthophoto dan topografi hasil foto drone dan design bulanan. Sumber data yang digunakan adalah data dari perusahaan kontraktor pertambangan, PT Pamapersada Nusantara. Variabel data yang dipakai untuk penelitian ini adalah adalah tinggi terbang drone, arah terbang, coverage area yang akan dipetakan, flight duration dan kualitas video drone.

\section{B.3 Teknik / Metode Analisis Data}

Metode yang digunakan dalam analisis data dalam penelitian ini adalah deskriptif kualitatif. Penelitian deskriptif kualitatif adalah penelitian yang menggambarkan atau melukiskan objek penelitian berdasarkan fakta-fakta yang tampak atau sebagaimana adanya. Nawawi danMartini 
(1996: 73). Pada penelitian ini akan dilakukan analisis terhadap parameter pengambilan video dan foto drone.

Proses analisis diawali dengan percobaan pengambilan video dengan melakukan trial dan error terhadap parameter ketinggian, arah terbang, durasi penerbangan (flight duration) dan kualitas video drone. Beberapa hasil uji coba penerbangan tersebut kemudian dibandingkan hasilnya dan akan dipilih video mana yang paling mudah dan jelas bagi pengawas untuk mengidentifikasikan deviasi di lapangan. Untuk coverage area yang akan dipetakan, diperhitungkan berdasarkan kapasitas baterai drone untuk sekali durasi penerbangan.

Setelah semua parameter pengukuran video drone didapat, kemudian dilanjutkan dengan pengambilan foto drone. Percobaan pengambilan foto drone juga dilakukan dengan trial dan error terhadap parameter ketinggian, arah terbang, durasi penerbangan (flight duration) dan kualitas video drone. Khusus untuk foto drone akan ditambahkan parameter overlay sidelap yaitu berapa persen foto drone tersebut saling beririsan dengan foto berikutnya agar ketika digabungkan menjadi orthophoto, hasilnya akan sesuai dengan kondisi tambang di lapangan. Untuk coverage area yang akan dipetakan juga diperhitungkan berdasarkan kapasitas baterai drone untuk sekali durasi penerbangan.

Tahap selanjutnya adalah melakukan analisa orthophoto hasil drone yang dibandingkan dengan desain bulanan pada periode yang sama. Hasil orthophoto yang diolah menjadi topografi juga akan dibandingkan terhadap desain bulanan dengan melakukan cross section di area-area yang dikerjakan. Dari kedua analisis ini kemudian akan dipakai sebagai acuan oleh engineer di lapangan untuk melakukan perencanaan berikutnya karena enginer telah mempunyai hasil monitoring aktual pergerakan tamabng secara horisontal dan vertikal.

Pada akhir periode setiap bulan, akan dibandingkan nilai MDA aktual 2017-2018 dengan nilai MDA setelah pengawas dan engineer telah memanfaatkan hasil video dan foto drone sebagai alat bantu pengawasan dan monitoring aktual progress tambang. Jika nilai MDA mengalami kenaikan, maka pemanfaatan drone. Alur diagram metode penelitian ini digambarkan pada gambar 5.

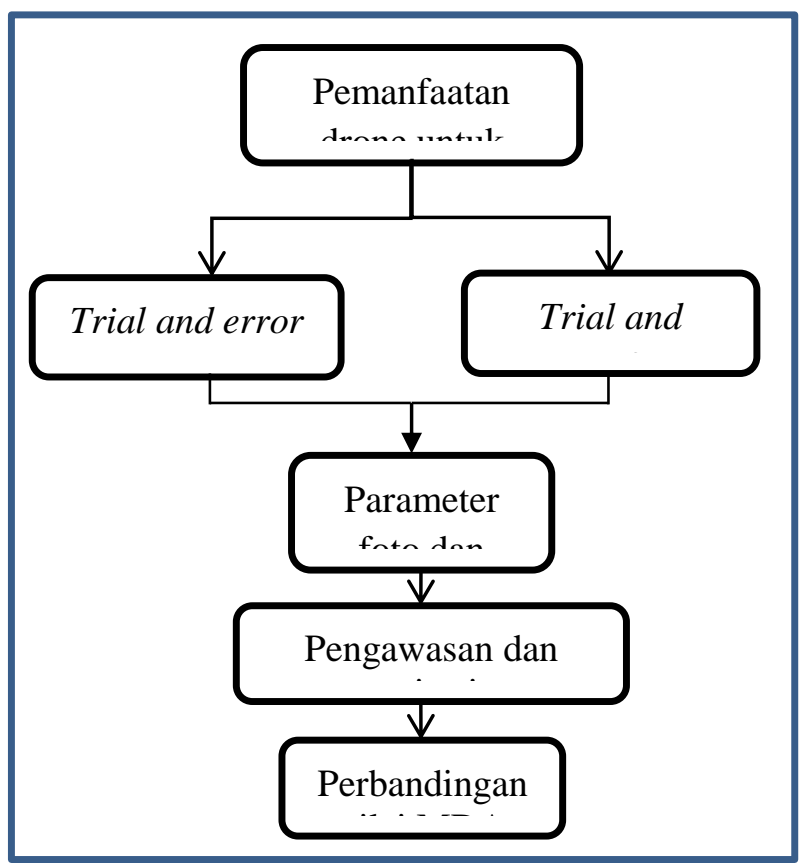

Gambar 5. Alur diagram rencana penelitian 


\section{HASIL DAN PEMBAHASAN}

Dari hasil percobaan pengambilan video dan foto udara dengan menggunakan drone dengan menggunakan beberapa parameter yang berbeda, didapatkan parameter yang paling optimal seperti yang ditunjukan pada tabel 1.

Tabel 1. Nilai MDA sebelum dan sesudah pemanfaatan drone

\begin{tabular}{|c|l|l|l|}
\hline No. & \multicolumn{1}{|c|}{ Parameter Teknis } & \multicolumn{1}{|c|}{ Orthophoto } & \multicolumn{1}{c|}{ Video Drone } \\
\hline 1 & Tinggi Drone & max. 150 m & max. 150 m \\
\hline 2 & Coverage & $\begin{array}{l}\text { All Pit (Minimal 60\% volume } \\
\text { produksi) }\end{array}$ & $\begin{array}{l}\text { All Pit (Minimal 60\% volume } \\
\text { produksi) }\end{array}$ \\
\hline 3 & Arah Terbang & menyesuaikan posisi pilot & Side Wall to Side Wall \\
\hline 4 & Overlap Sidelap & 75\% overlap, 60\% sidelap & - \\
\hline 5 & Flight Duration & $\begin{array}{l}\text { max. 16 menit, include mob demob } \\
\text { to waypoint }\end{array}$ & $\begin{array}{l}\text { max. 10 menit, include mob demob } \\
\text { to take off position }\end{array}$ \\
\hline 6 & Kualitas Video & & $4 \mathrm{~K}$ \\
\hline
\end{tabular}

Dari hasil percobaan pengambilan video dan orthophoto, tinggi drone paling optimal jika terbang diketinggian 150 meter. Untuk coverage pengambilan data mengikuti kapasitas baterai drone dengan rata-rata hasil percobaan di atas $60 \%$ dari keseluruhan area kerja sehingga ditetapkan minimal $60 \%$ dari volume produksi. Arah terbang drone yang paling optimal adalah side wall ke sisi side wall agar drone tidak banyak melakukan manuver saat terbang. Durasi penerbangan saat pengambilan video maksimal 10 menit dengan kualitas $4 \mathrm{~K}$ dan saat pengambilan foto maksimal 16 menit. Untuk bidang beririsan foto, didapatkan hasil yang optimal pada $75 \%$ secara overlap dan $60 \%$ secara sidelap.

Setelah pengawasan dan monitoring menggunakan teknologi drone, tambang terbentuk menjadi lebih rapi (gambar 6a dan 6b). Selain rapi, para engineer juga dapat langsung mengukur kesesuaian pembentukan desain secara horisontal melalui overlay orthophoto dengan desain (gambar 7) dan juga secara vertikal melalu hasil cross section (gambar 8)

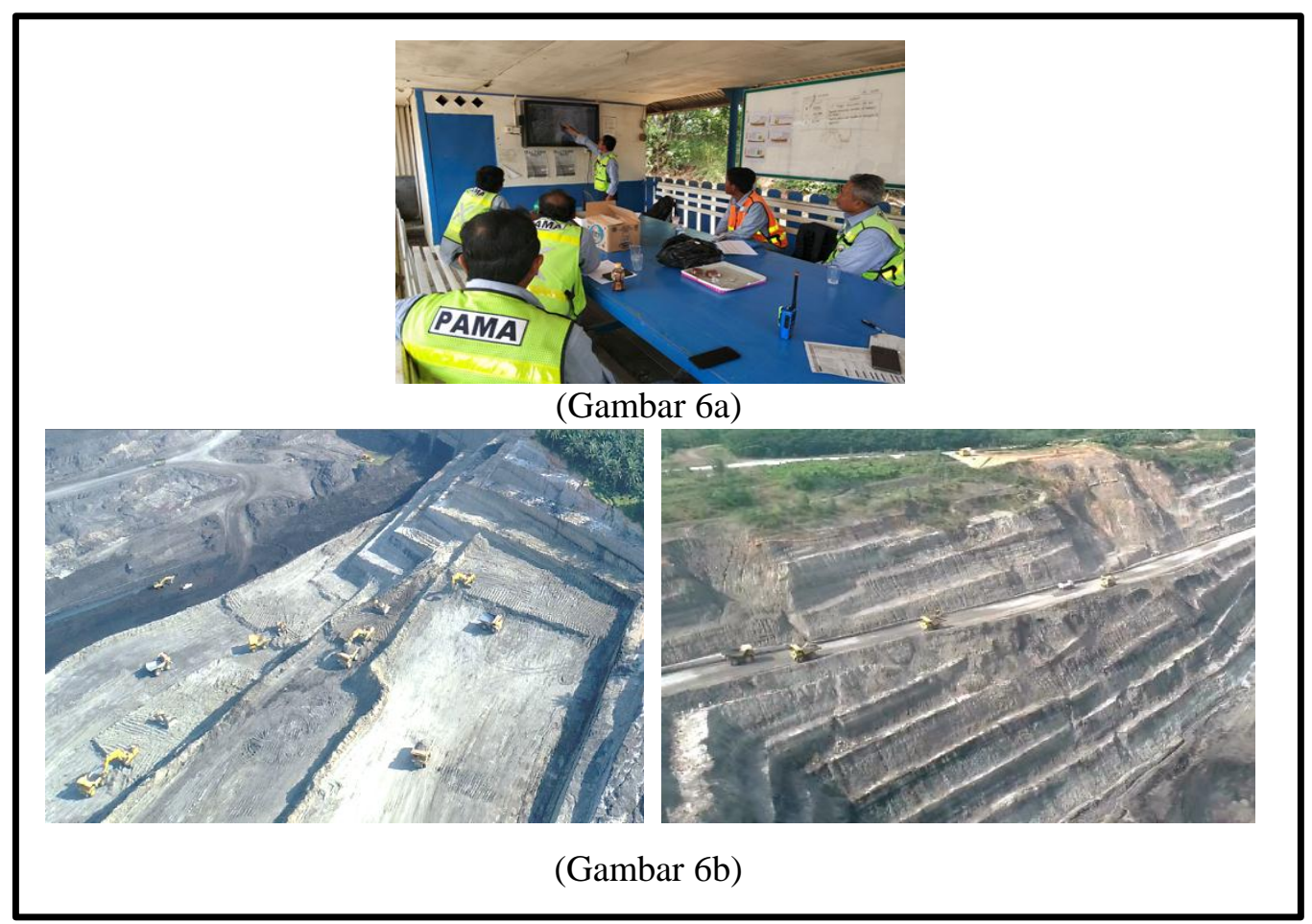

Gambar 6a. Hasil pemanfaatan video drone digunakan sebagai bahan evaluasi pengawas 
Gambar 6b. Gambar tambang yang terbentuk dengan rapi

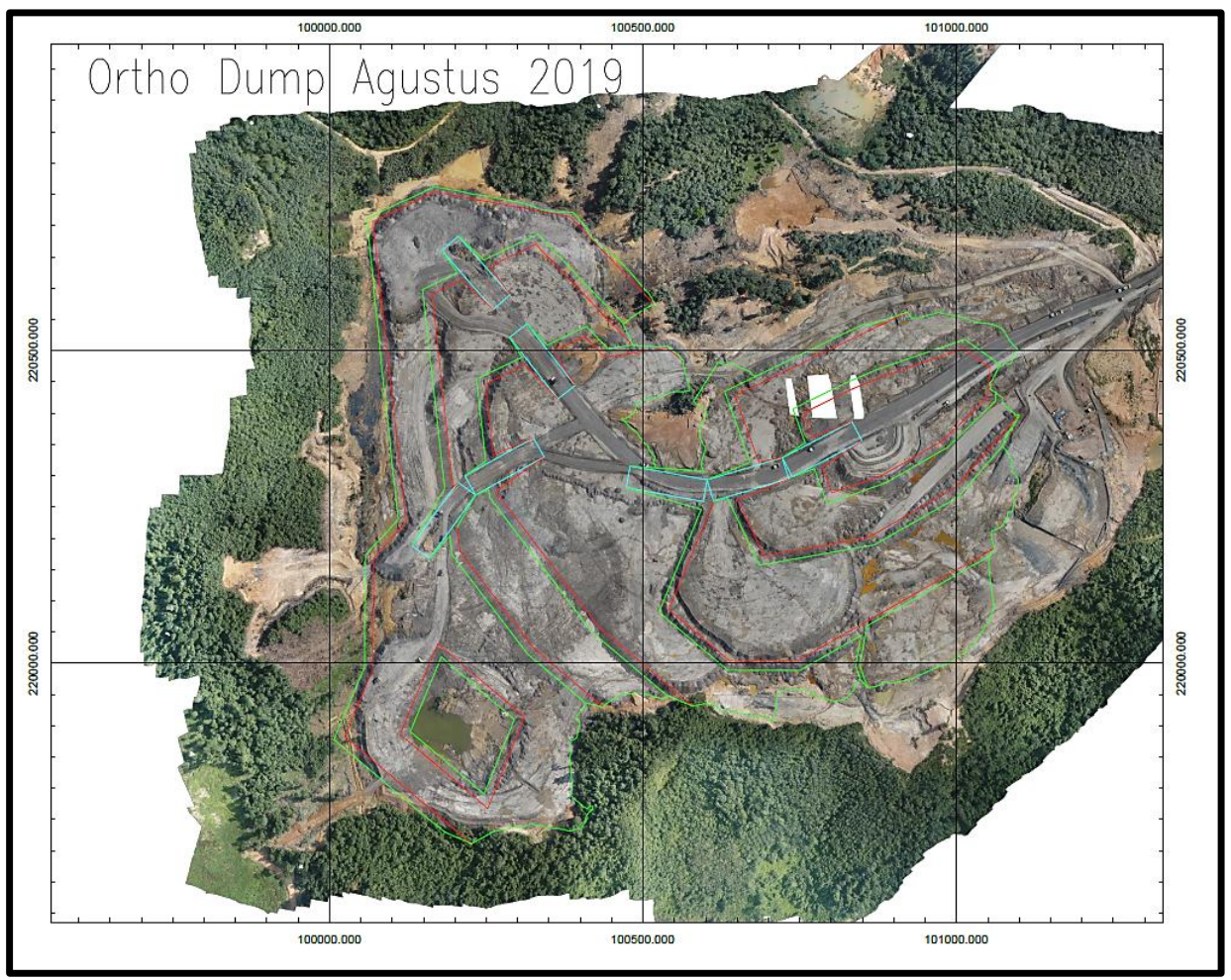

Gambar 7. Hasil overlay orthophoto dengan desain bulanan

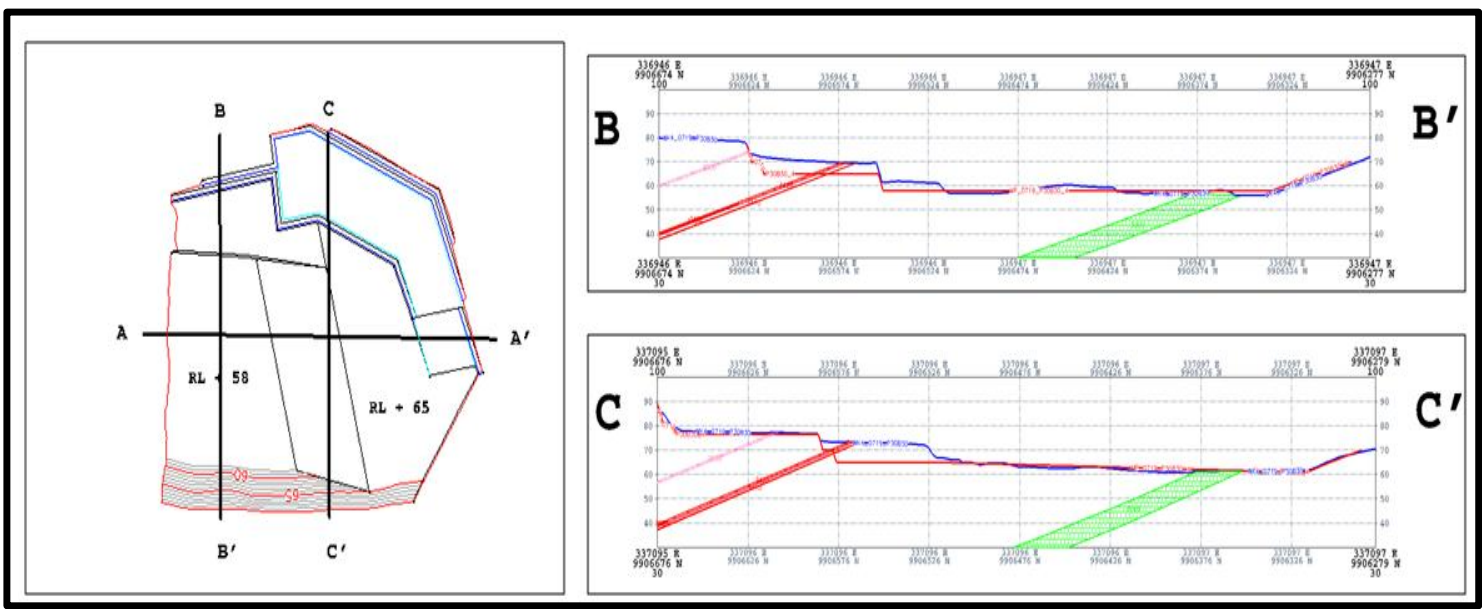

Gambar 8. Hasil cross section

Nilai MDA juga mengalami peningkatan menjadi 94,89\% setelah pengawasan dan monitoring penambangan menggunakan drone seperti yang ditunjukan pada tabel 2 .

Tabel 2. Nilai MDA sebelum dan sesudah pemanfaatan drone

\begin{tabular}{cc}
\hline Tahun & Nilai MDA \\
\hline 2017 & $91,31 \%$ \\
2018 & $92,27 \%$ \\
S1 2019 & $94,89 \%$
\end{tabular}


Dari tabel 2 di atas, nilai MDA mengalami peningkatan sebesar 3,58 \% dengan overcut menurun.

\section{KESIMPULAN}

Berdasarkan hasil perbandingan nilai MDA sebelum dan sesudah pemanfaatan teknologi drone yang telah dilakukan, dapat diambil kesimpulan sebagai berikut:

1. Pemanfaatan drone sebagai alat bantu pengawasan operasional penambangan pada tambang batubara terbuka sangat berguna bagi pengawas. Pengawas dilapangan dapat lebih mudah dan lebih cepat dalam menemukan deviasi yang terjadi dilapangan sehingga pengawas dapat segera melakukan tindakan perbaikan (corrective action).

2. Pemanfaatan hasil pemetaan topografi dari foto udara drone sebagai acuan perencanaan dan monitoring progress penambangan pada tambang batubara terbuka juga sangat membantu para engineer di lapangan untuk dapat menentukan area prioritas pengalian sesuai dengan area mana yang masih undercut jauh terhadap desain dan dapat menginformasikan kepada pengawas dilapangan area mana yang sudah mendekati desain sehingga area tersebut tidak overcut.

3. Pemanfaatan teknologi drone untuk monitoring akurasi perencanaan tambang batubara terbuka dapat meningkatkan nilai MDA sebesar 3,58\%

\section{UCAPAN TERIMA KASIH}

Terima kasih kepada PT. Pamapersada Nusantara khususnya tim Technical Service Engineer yang telah membantu memberikan ide dan data untuk peneltian ini.

\section{DAFTAR PUSTAKA}

Dokumentasi foto dan data-data Mine Design Accuracy diperoleh melalui: Technical Service Departement Divisi Engineering

Informasi mengenai batubara thermal di Indonesia diperoleh melalui situs internet: https://www.indonesia-investments.com/id/bisnis/komoditas/batu-bara/item236?

Informasi pengertian istilah-istilah drone dan penelitian deskriptif kualitatif diperoleh melalui situs internet: https://id.wikipedia.org 
PROSIDING TPT XXVIII PERHAPI 2019 